\title{
Prenatal and postnatal growth failure associated with maternal heterodisomy for chromosome 7
}

\author{
S Langlois, S L Yong, R D Wilson, L C Kwong, D K Kalousek
}

\begin{abstract}
The association of maternal uniparental disomy for chromosome 7 and postnatal growth failure has been reported in four cases and suggests the presence of genomic imprinting of one or more growth related genes on chromosome 7. However, in the reported cases, the possibility of homozygosity for a recessive mutation could not be excluded as the cause of the growth failure as in all cases isodisomy rather than heterodisomy for chromosome 7 was present. We report a case of prenatal and postnatal growth retardation associated with a prenatal diagnosis of mosaicism for trisomy 7 confined to the placenta. DNA typing of polymorphic markers on chromosome 7 has established that the zygote originated as a trisomy 7 with two maternal and one paternal chromosomes 7 with subsequent loss of the paternal chromosome resulting in a disomic child with maternal heterodisomy for chromosome 7. The growth failure seen in this child with heterodisomy 7 lends strong support to the hypothesis of imprinted gene(s) on chromosome 7 .
\end{abstract}

( $($ Med Genet 1995;32:871-875)

Department of Medical Genetics, University of British Columbia, BC Children's Hospital, 4500 Oak Street, Vancouver, British Columbia V6H 3N1, Canada $S$ Langlois $S$ L Yong

$R$ D Wilson

L C Kwong

Department of Obstetrics and Gynecology, University of British Columbia,

Vancouver, BC, Canada

R D Wilson

Department of Pathology, University of British Columbia,

Vancouver, BC, Canada

D K Kalousek

Correspondence to: Dr Langlois.

Received 17 April 1995 Revised version accepted for publication 19 June 1995
Uniparental disomy (UPD), the inheritance of two homologous chromosomes from one parent in a disomic cell, has been recognised for a number of chromosomes and its phenotypic effect appears to be chromosome specific. Maternal uniparental disomy for chromosome 15 is associated with Prader-Willi syndrome $\mathrm{e}^{1-3}$ and paternal uniparental disomy for chromosome 15 with Angelman syndrome. ${ }^{4}$ Maternal and paternal uniparental disomy for chromosome 14 have been reported. Paternal UPD 14 was found in a patient born with multiple congenital anomalies including bilateral subarachnoid hygromas, short neck with webbing, small thoracic cage, marked angulations of the ribs, bilateral simian creases, and facial dysmorphism who presented at 9 years of age with severe mental retardation, severe kyphoscoliosis, a seizure disorder, and coarse facial features. ${ }^{5}$ Maternal UPD 14 has been reported in three patients presenting with an abnormal phenotype. ${ }^{6-8}$ However, UPD is not always associated with an abnormal phenotype. Maternal UPD for chromosomes $13^{9}$ and $22^{10}$ and paternal UPD for chromosome $21^{11}$ have been described in subjects with a normal phenotype.

It has been suggested that maternal UPD 7 is associated with significant postnatal growth failure on the basis of three cases of maternal isodisomy for chromosome $7^{12-14}$ and one case of uniparental isodisomy for paternal $7 \mathrm{p}$ and maternal 7q. ${ }^{15}$ Paternal isodisomy for chromosome 7 has been reported in a child with a recessive condition, congenital chloride diarrhoea, but normal growth. ${ }^{16}$ These cases raised the possibility of genomic imprinting of one or more growth related genes on the long arm of chromosome 7 with a paternal contribution being necessary for normal growth. However, because in all four cases of growth failure isodisomy rather than heterodisomy for chromosome $7 \mathrm{q}$ was present, homozygosity for a recessive mutation could not be excluded as the cause of the growth failure. In this report, a child who presented with intrauterine growth retardation and who has shown postnatal growth failure despite being otherwise completely normal is shown to have maternal heterodisomy for chromosome 7 . This represents the first case of complete heterodisomy for chromosome 7 and supports the hypothesis of imprinted growth related genes on chromosome 7 .

\section{Materials and methods}

CLINICAL INFORMATION

The proband was born to a 42 year old gravida 2 , term 1 , aborta 0 , living 1 mother at 36 weeks' gestation. Chorionic villi sampling (CVS) was performed at 9 weeks 6 days for an indication of advanced maternal age. Cultured preparations of CVS showed complete non-mosaic trisomy 7. Amniotic fluid cell culture performed at 12 weeks 6 days of gestation showed a normal female karyotype. No evidence of trisomy 7 was found. A diagnosis of confined placental mosaicism (CPM) for trisomy 7 was made. At 17 weeks' gestation, the maternal serum alphafetoprotein level was found to be raised at 2.75 MOM. A repeat amniocentesis was done following discussion of neural tube defect risks and the amniotic alphafetoprotein level was normal. At 29 weeks' gestation, an ultrasound identified intrauterine growth retardation (IUGR) (table 1). At 31 weeks oligohydramnios was diagnosed. There were no other complications such as placenta abruptio or premature rupture of membranes, but at 36 weeks' gestation, a caesarian section was performed for indications of IUGR, oligohydramnios, and breech presentation. A female infant was delivered with Apgar scores of 7 at one minute and 9 at five minutes. Her birth weight was $1560 \mathrm{~g}(-3 \mathrm{SD})$, length $41.5 \mathrm{~cm}$ $(-3 \mathrm{SD})$, and head circumference $31.3 \mathrm{~cm}$ ( $-1 \mathrm{SD})$. There were no dysmorphic features 
Table 1 Serial ultrasound assessment

\begin{tabular}{lll}
\hline Estimated gestational age & U/S findings & Centile \\
\hline $7^{+6}$ & CRL 17 mm & 50 th \\
$9^{+6 *}$ & CRL 26 mm & 10 th \\
$11^{+6}$ & CRL 46 mm & 25 th \\
$12^{+6}+$ & CRL $59 \mathrm{~mm}$ & 25 th \\
$18^{+6}$ & BPD $39 \mathrm{~mm} \mathrm{~F} \mathrm{23} \mathrm{mm}$ & 10 th \\
$26^{+5}$ & BPD 65 mm AC 215 mm F 43 mm & 10 th \\
$29^{+5}$ & BPD 73 mm AC 222 mm F 51 mm & $<10$ th \\
$31^{+5}$ & BPD 76 mm AC 230 mm F 52 mm & $<10$ th \\
$35^{+4}$ & oligohydramnios & $<10$ th \\
\hline
\end{tabular}

$\mathrm{CRL}=$ crown rump length, $\mathrm{BPD}=$ biparietal diameter, $\mathrm{AC}=$ abdominal circumference * Chorionic villi sampling. † Amniocentesis.

noted and the remainder of her physical examination was normal. The placenta weighed $380 \mathrm{~g}$.

At 2 years of age, she had a weight of $9 \mathrm{~kg}$ ( $-3 \mathrm{SD})$, length $80.4 \mathrm{~cm}(-2 \mathrm{SD})$, and head circumference $49 \mathrm{~cm}$ (50th centile). Her developmental milestones were normal as assessed by the Denver Developmental Screening Test. At 3 years 9 months of age, her height is $91 \mathrm{~cm}(-2 \mathrm{SD}$ to $-3 \mathrm{SD})$, her weight $12 \cdot 2 \mathrm{~kg}$ $(-2 \mathrm{SD}$ to $-3 \mathrm{SD})$. Her father and mother measure $183 \mathrm{~cm}$ and $178 \mathrm{~cm}$ respectively. Therefore her height is $-4 \mathrm{SD}$ for her expected height for her midparental height. ${ }^{17}$

\section{CYTOGENETIC STUDIES}

Heparinised umbilical cord blood taken at birth was cultured for 72 hours at $37^{\circ} \mathrm{C}$ in RPMI 1640 supplemented with $50 \%$ FBS and antibiotics. $T$ cell mitosis was stimulated with phytohaemagglutinin. After harvesting, slides were banded and stained with $0.25 \%$ trypsin and Giemsa stain. One hundred metaphases were examined for the presence of trisomy 7 .

Amnion, chorion, and villi from various areas of the placenta were separately digested in a $0.1 \%$ collagenase solution, centrifuged, and cells plated in T-25 flasks. After growth in supplemented F-10 medium, cells were harvested, banded, stained, and examined for the presence of trisomy 7 . Thirty metaphases from each placental tissue were examined. Cultured cells from amnion were examined by fluorescence in situ using alpha satellite centromeric probe D7Z1 and D7Z2 (Oncor).

\section{MOLECULAR STUDIES}

DNA was extracted from blood from both parents and the child and from chorion and amnion using a technique described elsewhere. ${ }^{18}$ Ten dinucleotide repeat polymorphisms were typed on all DNA samples. Primers for markers D7S513, D7S516, EGF ELN, D7S482, D7S440, D7S515, D7S495, and D7S483 were obtained from Research Genetics (Huntsville, AL). All markers were typed following a similar protocol: $0.5 \mu \mathrm{l}$ of $20 \mu \mathrm{mol} /$ 1 of each primer, $2 \mu \mathrm{l}$ of $10 \times \mathrm{Taq}$ polymerase buffer, $2 \mu \mathrm{l}$ of dNTP mix of dATP, dCTP, $\mathrm{dGTP}$, and dTTP at $20 \mu \mathrm{mol} / \mathrm{l}$ each, $0.6 \mu \mathrm{l}$ of $\mathrm{MgCl}, 0.1 \mu \mathrm{l}$ of $\alpha^{32} \mathrm{P}-\mathrm{dCTP}$ at $10 \mathrm{mCi} / \mathrm{ml}$, $0.2 \mu \mathrm{l}$ of $\mathrm{Taq}$ polymerase at $5 \mathrm{U} / \mu \mathrm{l}$, and $100 \mathrm{ng}$ of DNA were amplified through 35 cycles consisting of 40 seconds at $94^{\circ} \mathrm{C}, 30$ seconds at $55^{\circ} \mathrm{C}$, followed by an extension period of two minutes at $72^{\circ} \mathrm{C}$. The alleles were separated by electrophoresis in an $8 \%$ denaturing polyacrylamide DNA sequencing gel. All gels were fixed and dried and were exposed to $x$ ray film for 24 hours at room temperature. The polymorphic dinucleotide repeat in intron $17 \mathrm{~b}$ of the cystic fibrosis transmembrane conductance regulator gene was analysed as previously described. ${ }^{19}$

\section{Results}

Chromosomes from cord blood showed a normal 46,XX karyotype in 100 cells examined, while cultured cells from placental tissues confirmed the trisomy 7 diagnosed prenatally. In both chorion and villi, $100 \%$ of cells were trisomic (fig 1). Amnion cultures showed 10\%

Figure 1 Karyotype of trisomy 7 seen in both chorionic villi and term placenta. 


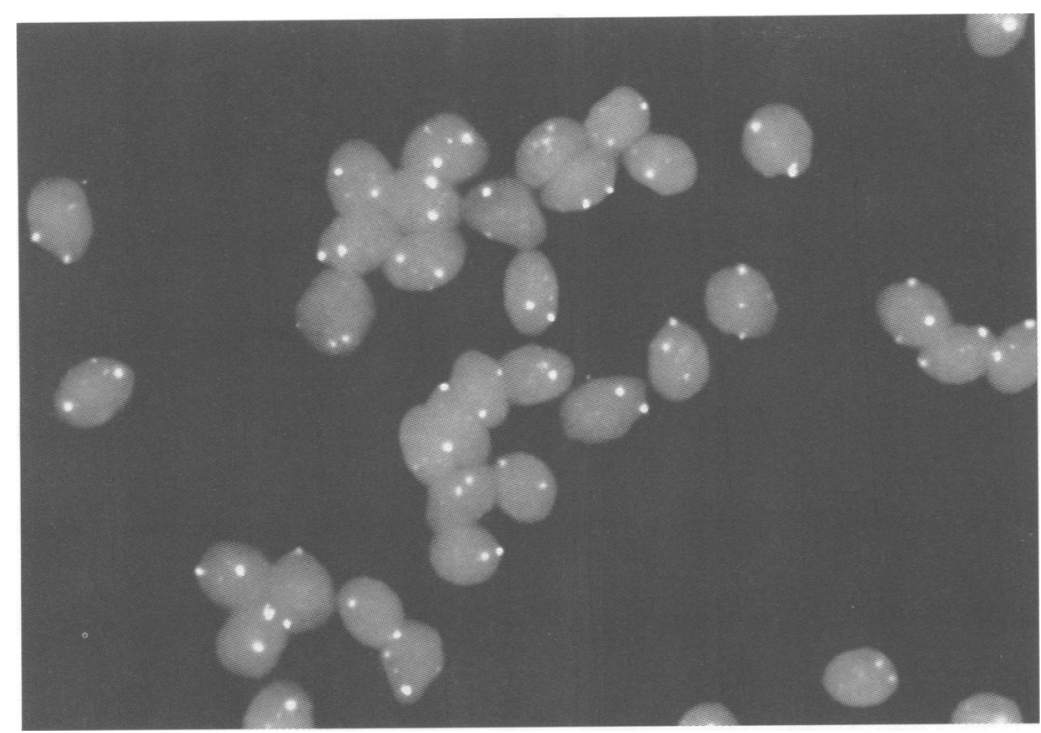

Figure 2 Interphase analysis of digested amnion showing two signals for chromosome 7 in all analysed cells. trisomy 7 cells. This was considered to represent contamination from chorion as FISH analysis of 1000 cultured amnion cells showed complete disomy for chromosome 7 (fig 2), thus confirming the prenatal diagnosis of CPM for trisomy 7 .

The map position of the ten dinucleotide repeat polymorphisms and results of the typing done on blood from the parents and child, chorion and amnion are shown in table 2. For the dinucleotide repeat polymorphisms at the ELN, D7S482, D7S440, D7S515, and CFTR loci, the proband does not share an allele in common with her father but has inherited both alleles from her mother. In addition, for the same markers and for marker D7S516, the chorion was found to have one allele which is not seen in the amnion or child and is in common with the father. These markers allow the diagnosis of maternal uniparental disomy for chromosome 7 to be made in the proband. In addition, for eight of the 10 (CA)n polymorphisms typed, including EGF and D7S482 which flank the centromere, the mother is heterozygous and both maternal alleles are present in chorion, amnion, and child indicating that the conceptus began as a trisomy 7 secondary to maternal meiotic I non-disjunction error with a postzygotic loss of the paternal allele leading to maternal heterodisomy in this child.

Table 2 Molecular analysis

\begin{tabular}{lllll}
\hline Marker & Mother & Father & Child/amnion & Chorion \\
\hline p arm & & & & \\
D7S513 & 2,3 & 1,2 & 2,3 & 2,3 \\
D7S516 & 1,2 & 2,3 & 1,2 & $1,2,3$ \\
Pericentromeric & 1,2 & 2,3 & 1,2 & $1,2,3$ \\
EGF & 2,2 & 1,3 & 2,2 & 2,3 \\
ELN & 1,2 & 3,3 & 1,2 & $1,2,3$ \\
D7S482 & 1,2 & 3,4 & 1,2 & $1,2,3$ \\
q arm & 2,4 & 1,3 & 2,4 & $1,2,4$ \\
D7S440 & 1,1 & 2,2 & 1,1 & 1,2 \\
D7S515 & 1,2 & 1,1 & 1,2 & 1,2 \\
CFTR-intron 17 CA & 2,3 & 1,2 & 2,3 & $1,2,3$ \\
D7S495 & & & & \\
D7S483 & & &
\end{tabular}

Discussion

The association of postnatal growth failure with uniparental disomy for chromosome 7 has previously been reported. In 1988, Spence $e t$ al ${ }^{12}$ reported the first case of UPD in humans in a patient with cystic fibrosis (CF), short stature, and growth hormone deficiency. At the age of 16 , despite growth hormone therapy, her height was noted to be $130 \mathrm{~cm}(-5 \mathrm{SD})$. This patient was found on molecular analysis to be isodisomic for her maternal chromosome 7 .

In 1989 , Voss $e$ al $^{13}$ reported the second case of maternal isodisomy 7 in another patient with CF who had severe growth retardation. This patient was small for gestational age with a birth weight at 38 weeks' gestation of 1770 $(-4 \mathrm{SD})$ and continued to display poor growth postnatally. At the age of 4 years his height was $87 \mathrm{~cm}(-3.5 \mathrm{SD})$ which is at the 50th centile for age 2 years.

The third reported case of maternal UPD for chromosome 7 (partial isodisomy) was by Spotila et al. ${ }^{14}$ Their patient was ascertained through studies of the COL1A2 gene in patients with osteoporosis. He had a history of intrauterine growth retardation. He was born at term weighing $2048 \mathrm{~g}(-4 \mathrm{SD})$. At the age of $8 \frac{1}{2}$ years, he was enrolled in a growth hormone treatment study because of his significant short stature. At the age of 30 years, he measured $143.7 \mathrm{~cm}(-4 \mathrm{SD})$. Molecular analysis showed that although his mother was heterozygous for a mutation in the COL1A2 gene and his father was normal, he was found to be homozygous for the mutation found in his mother. Five polymorphic markers on chromosome 7 showed only maternal inheritance and at eight out of nine loci on chromosome 7 analysed the patient was homozygous whereas his mother was heterozygous. Taken together these results indicate that the patient has partial isodisomy for chromosome 7 and heterodisomy for a portion of the short arm of chromosome 7 owing to a double crossover event involving the short arm.

The fourth case of maternal isodisomy $7 q$ was reported in a child who was shown prenatally to have an unusual karyotype of $46, \mathrm{XX}$, $t(7 ; 7)(7 p 7 p ; 7 q 7 q)$ in $18 / 18$ clones examined. Her birth weight was $3336 \mathrm{~g}$ (25th-50th centile), her length was $48 \mathrm{~cm}$ (10th-25th centile), and her head circumference was $35 \mathrm{~cm}$ (75th90 th centile). She presented with postnatal growth retardation and at 6 months her weight was $5.11 \mathrm{~kg}(-3.5 \mathrm{SD}$ to $-4 \mathrm{SD})$, her length $58.5 \mathrm{~cm}(-2 \mathrm{SD})$, and her head circumference $76 \mathrm{~cm} \quad(-4 \mathrm{SD})$. Her developmental milestones were normal. Molecular studies showed isodisomy for paternal $7 \mathrm{p}$ and maternal isodisomy for $7 \mathrm{q} .{ }^{15}$

The degree of short stature $(-3.5$ to -5.5 SD) described in these reported UPD 7 cases is too severe to be accounted for exclusively by the underlying medical condition that led to the ascertainment of three of the four cases. The fourth case, the patient with maternal isodisomy $7 \mathrm{q}$, has no underlying illness to account for her short stature. Furthermore, the information provided in two of the four reported cases indicated the presence 
of prenatal growth failure as both children were reported to be small for gestational age. In the present report, the maternal UPD for chromosome 7 was ascertained through a diagnosis of CPM for trisomy 7 on analysis of chorionic villi and amniocytes. The pregnancy was closely monitored by serial ultrasound assessments because of the increase risk of obstetrical complications associated with CPM. In the first trimester, fetal biometry was at the 25 th centile. Serial assessments in the second and third trimester showed decreased fetal growth and at 29 to 36 weeks' gestation, fetal measurements were below the 10th centile for biparietal diameter, abdominal circumference, and femur length (table 1). At birth the baby was $-3 \mathrm{SD}$ for weight and length. The infant has shown normal developmental milestones and has had no medical problems. However, there has been poor postnatal catch up growth and at 3 years 9 months of age her weight and height are between -2 and -3 SD for her age and -4 SD for her expected height in view of midparental height. The absence of postnatal catch up growth in this patient suggests that placental dysfunction secondary to CPM for trisomy 7 is unlikely to be the only cause of her growth failure at birth. Other cases of growth failure associated with placental mosaicism have shown catch up growth postnatally. ${ }^{2021}$ The present case together with the four previously reported cases indicates a causal association between maternal uniparental disomy for chromosome 7 and prenatal and postnatal growth failure. The degree of postnatal growth failure appears to be variable. The heights of the four previously reported patients ranged from $-3 \mathrm{SD}$ to $-4 \mathrm{SD}$ from the mean. However, mean parental heights were not reported. It is possible that the variability would be less if all heights were expressed in terms of deviation from expected height for midparental height. Certainly, the height of the patient presented in this report has been between -2 and $-3 \mathrm{SD}$, which on its own suggests less severe growth failure. However, her height is $-4 \mathrm{SD}$ when compared to her expected height for her midparental height.

Two different mechanisms can be postulated to explain the association of maternal UPD and growth failure. (1) The presence of UPD increases the risk for homozygosity for a recessive gene causing growth failure. (2) Gene(s) that regulate growth on chromosome 7 are imprinted with a paternal contribution required for normal expression. Both mechanisms are plausible for the first four cases of UPD reported, as two cases represented total maternal isodisomy and two maternal isodisomy for the long arm of chromosome 7 . The present case of maternal heterodisomy for chromosome 7 suggests that imprinting is the most likely cause of the growth failure. Homozygosity for a recessive gene is much less likely as a double recombination between two markers tested would be required for a portion of chromosome 7 to be isodisomic. The presence of growth related genes that have been mapped to human chromosome $7 \mathrm{q}$ and are syntenic with regions in the mouse genome that are known to be imprinted lend further support to the causal role of imprinting in the growth failure seen in cases of maternal UPD $7 .{ }^{14}$

Uniparental heterodisomy can result from several types of errors in chromosome segregation. ${ }^{12}$ The molecular analysis in this case has established that the maternal heterodisomy occurred owing to loss of the paternal chromosome 7 in early cell division in a trisomic 7 zygote, which resulted from a maternal meiotic error. Molecular studies of non-disjunction in trisomy 7 have not been reported. Studies of trisomy $16,{ }^{22}$ trisomy $18,{ }^{23}$ and trisomy $21^{24}$ have shown that the majority of trisomies are attributable to maternal meiosis I non-disjunction error. Our findings suggest that the same mechanism has occurred in this conceptus. Trisomy 7 is a lethal aneuploidy which accounts for $0.9 \%$ of spontaneous abortions. ${ }^{25}$ Trisomy 7 zygotes rescued by a postzygotic mutation leading to a diploid embryo/fetus would have a $1 / 3$ risk of maternal heterodisomy for chromosome 7 .

In conclusion, maternal heterodisomy and isodisomy for chromosome 7 have been associated with intrauterine growth retardation and postnatal growth failure. Although identification of additional cases and long term follow up is needed to define the clinical spectrum of this genotype better, it is important to consider testing the UPD 7 in cases of CPM for trisomy 7 and in patients with a history of unexplained IUGR and postnatal growth failure.

This work was supported by the Medical Research Council of Canada grant No MA-12152.

1 Nicholls RD, Knoll JHM, Butler MG, Karam S, Lalande M Genetic imprinting suggested by maternal heterodisomy in nondeletion Prader-Willi syndrome. Nature 1989;342: $281-5$.

2 Robinson WP, Bottani A, Yagang X, et al. Molecular, cytogenetic and clinical investigations of Prader-Willi syn drome patients. Am f Hum Genet 1991;49:1219-34

3 Mascari MJ, Gottlieb W, Rogan PK, et al. The frequency of uniparental disomy in Prader-Willi syndrome. Implications for molecular diagnosis. $N$ Engl 7 Med 1992; 326:1599-607.

4 Malcolm S, Clayton-Smith J, Nichols $M$, et al. Uniparental paternal disomy in Angelman's syndrome. Lancet 1991, 337:694-7.

5 Wang JCC, Passage MB, Yen PH, Shapiro LJ, Mohandas TK. Uniparental heterodisomy for chromosome 14 in phenotypically abnormal familial balanced 13/14 robphenotypically abnormal familial balanced $13 / 14$ rob1069-74.

6 Temple IK, Cockwell A, Hassold T, Pettay D, Jacobs P. Maternal uniparental disomy for chromosome 14. f Med Genet 1991;28:511-14.

7 Pentao L, Lewis RA, Ledbetter DH, Patel PI, Lupski JR. Maternal uniparental isodisomy of chromosome 14: asMaternal uniparental isodisomy of chromosome 14: association with autosomal recessive

Am $\mathcal{F}$ Hum Genet 1992;50:690-9.
8 Healey S, Powell F, Battersby M, Chenevix-Trench G McGill J. Distinct phenotype in maternal uniparental disomy of chromosome 14. Am f Med Genet 1994;51 147-9.

9 Slater H, Shaw JH, Dawson G, Bankier A, Forrest SM. Maternal uniparental disomy of chromosome 13 in phenotypically normal child. 7 Med Genet 1994;31:644-6.

10 Schinzel AA, Basaran S, Bernasconi F, Karaman B, YukselApak M, Robinson WP. Maternal uniparental disomy 22 has no impact on the phenotype. Am $\mathcal{f}$ Hum Genet 1994 54:21-4.

11 Blouin JL, Avramopoulos D, Pangalos C, Antonarakis SE. Normal phenotype with paternal uniparental isodisom for chromosome 21. Am f Hum Genet 1993;53:1074-8.

12 Spence JE, Perciaccante RG, Greig GM, et al. Uniparental disomy as a mechanism for human genetic disease. $A m \mathcal{F}$ Hum Genet 1988;42:217-26.

13 Voss R, Ben-Simon E, Avital A, et al. Isodisomy of chromosome 7 in a patient with cystic fibrosis: could unimosome 7 in a patient with cystic fibr $7 \mathrm{H}$ um $\mathrm{Gem}$ 1988;45:373-80.

14 Spotila LD, Sereda L, Prockop DJ. Partial isodisomy for maternal chromosome 7 and short stature in an individual 
with a mutation at the COLIA2 locus. Am $\mathcal{F}$ Hum Genet 1992:51:1396-405.

15 Eggerding FA, Schonberg SA, Chehab FF, Norton ME, Cox VA, Epstein CJ. Uniparental isodisomy for paterna $7 \mathrm{p}$ and maternal $7 \mathrm{q}$ in a child with growth retardation. Am ₹ Hum Genet 1994;55:253-65.

16 Hoglund P, Holmberg C, de la Chapelle A, Kere J. Paterna isodisomy for chromosome 7 is compatible with normal growth and development in a patient with congenita chloride diarrhea. Am f Hum Genet 1994;55:747-52.

17 Tanner JM, Goldstein H, Whitehouse RH. Standards for children's height at ages 2-9 years allowing for height of parents. Anch Dis Child 1970;45:755-62.

18 Hayden MR, Kirk H, Clark C, et al. DNA polymorphisms in and around the Apo-A1-CIII genes and genetic hyper-

19 Zielenski J, Markiewicz D, Rininsland F, Rommens J, Tsui LC. A cluster of highly polymorphic dinucleotide repeats in intron $17 \mathrm{~b}$ of the cystic fibrosis transmembrane conductance regulator (CFTR) gene. Am f Hum Genet 1991 49:1256-62.
20 Fryburg JS, Dimaio MS, Mahoney MJ. Postnatal placental confirmation of trisomy 2 and trisomy 16 detected at chorionic villus sampling: a possible association with intrauterine growth retardation and elevated maternal serum alpha-fetoprotein. Prenat Diagn 1992;12:157-62.

21 Fryburg JS, Dimaio MS, Yang-Feng TL, Mahoney MJ. Follow-up of pregnancies complicated by placental mosaicism diagnosed by chorionic villus sampling. Prenat Diagn 1993;13:481-94.

22 Hassold TJ, Pettay D, Freeman SB, Grantham M, Takaesu N. Molecular studies of non-disjunction in trisomy $16 . \mathcal{J}$ Med Genet 1991;28:159-62.

23 Fisher JM, Harvey JF, Lindenbaum RH, Boyd PA, Jacobs PA. Molecular studies of trisomy 18. Am $\mathcal{F}$ Hum Genet 1993;52:1139-44.

24 Antonarakis SE, and the Down Syndrome Collaborative Group. Parental origin of the extra chromosome in trisomy 21 as indicated by analysis of DNA polymorphisms. $N$

25 Hassold TJ, Jacobs PA. Trisomy in man. Annu Rev Genet 1984;18:69-97. 